\title{
Is there bias in editorial choice? Yes.
}

\author{
Khaled Moustafa*
}

\begin{abstract}
Nature has recently published a Correspondence claiming the absence of fame biases in the editorial choice. The topic is interesting and deserves a deeper analysis than it was presented because the reported brief analysis and its conclusion are somewhat biased for many reasons, some of them are discussed here. Since the editorial assessment is a form of peer-review, the biases reported on external peer-reviews would, thus, apply to the editorial assessment, too. The biases would be proportional to the elitist level of a journal; the more elitist a journal, the more biased its decisions, unavoidably. The bias could be intentional or unintentional, conscious or subconscious, reflecting our imperfect human nature.
\end{abstract}

Keywords : Editorial bias, Fame bias, Peer review, Manuscript submission, Peer review Bias, Blind peer review

Nature has recently published an 'auto-congratulator' Letter (Mahian 2015) in which the authors report that no fame biases would exist in editorial choice relating to the corresponding author in Letters submitted to Nature, based on a tiny sample (239 authors) analyzed. The topic is interesting and deserves a deeper analysis than it was presented by the author(s) because the authors' analysis and its conclusion are biased for many reasons.

First, the authors do not show the data they used neither they have showed how the analysis was done or whether it was statistically significant. The numbers of Letters submitted to-/rejected by-Nature are not shown, nor the precise profiles of accepted/rejected authors. As readers, we expect to view the list of data used in the analysis on which the authors have built their conclusion. We expect to see the data at least as a supplementary file, but surprisingly the supplementary file appended to the Letter is a list of co-authors, confusing the readers about the number of authors and about the purpose behind a list of co-authors provided as a supplementary file instead of presenting data sheet to eventually let readers judge the issue by themselves.

Concealing the data and analyzing the scientific status of corresponding authors over a short period (1 year only), with a small sample of 239 Letters out of thousands submissions/rejections per year, and then claiming that no fame bias would exist at editorial choices is rather a shallow analysis. From a statistical viewpoint, the analysis is biased to draw a confirmative conclusion as the author's was. The size of the sample is too small and not representative because all the manuscripts submitted to a journal are firstly assessed by editors and, thus, the acceptance/rejection could be biased for Letters as it could be biased for any other type of manuscript. During the last 17 years (1997-2013), the average number 
of submissions to Nature was about 9589 submissions per year, and the acceptance average was about $9.11 \%$ (http://www.nature.com/nature/authors/get published). To make a worthwhile analysis, the authors have had to extent their analysis to cover this period with the largest sample possible and to include all manuscripts types, not only Letters, as the fates of all manuscripts, including Letters, are decided by the editors' choices, either at the beginning or at the end of the assessment. If an editor decides not to send a manuscript out for external peer-review, the whole evaluation process is stopped early. An editor can also overweigh a negative reviewer's report that recommends rejection over another positive report that recommends acceptance, or inversely, based on subjective or personal appreciation, particularly when disagreements and diverse comments are made to authors (Onitilo et al. 2013).

Second, according to the authors' conclusion, about $54 \%$ of 239 authors (or 129 of them) were classified as "established scholars" and some $13 \%$ came from developing countries. Although the attribute of 'established scholar' is subjective and debatable, as presented by the author by limiting the scientific reputation to three criteria (publishing in two journals only; Nature and Science, and high h-index), the authors also do not specify explicitly whether the $13 \%$ of authors from developing countries were out of the 129 established authors or out of the total 239 authors surveyed in unshown analysis. In either case, anyway, the analysis is still unreliable because $13 \%$ out of 129 or 239 authors would remain biased since it reflects merely 16 or 31 authors respectively, out of thousands rejected as stated by Nature itself (http://www.nature.com/nature/authors/get_published).

Third, the developing countries involved in the analysis are also not shown or mentioned, neither the basis of their inclusion. In other word, what makes a corresponding author as originated from a developing country? Is it the author's name or his affiliation or both? Neither case is valid, because it is common now that a fame scientist from a developed country can work in a developing country or vice versa. With multiple coauthorship lists, fame biases would exist wherever fame scientists work. If Einstein for example submitted a paper while working in a developing country or he was a co-author of a manuscript coming from a developing country, an Einstein's celebrity bias would follow him whatever the country he works in, and whoever the corresponding co-authors he delegates.

Forth, the three criteria (publication in Science or Nature or high h-index) set by the authors as the criteria of an 'established scholar' are debatable, particularly the $\mathrm{h}$-index (Bornmann and Daniel 2009). The author overlooks the fact that Nature and Science are only two journals among thousands others, and scientists in various fields could also be 'established scientists' by publishing in specialized journals in their respective domains without having papers in these two journals.

Fifth, the criterion of the top 100 universities ranking is also biased because it compares incomparable institutions that are different in almost all the infrastructures. From 
a scientific viewpoint, such rankings are also invalid because they are based on biased criteria, and any analysis based on biased criteria will, in turn, be biased too.

Sixth, an editor has basically a double role as a reviewer and editor at the same time. $\mathrm{S} /$ he assesses manuscripts and makes decisions; accept, send out for external peer review or reject (Grace 2004). In their roles as evaluators, editors are humans subject to the foibles of that species (Spier 2002). Potential fame biases would thus exist at both editorial and external reviews, whatever the manuscript type is (Letters or others). Nature itself has recognized it indirectly when it has recently offered to authors a double blind peer-review option, which should increase the authorship diversity and profiles (Darling 2015). Since editors are peer-reviewers in their roles of assessors, a bias would thus exist at the editorial level, in the same way it would exist at the external peer-review, for which the blind review was proposed to reduce.

Fame biases are also obviously seeable in the instructions of some journals that condition the submission of papers to senior or 'expert' scientists. Other journals state it clearly; manuscripts should not be submitted by graduate students or postdocs trainees!

Thus, the answer to the initial question; "is there a fame bias in editorial choice?" is clearly Yes. It is confirmed by many recent and old reports (Manchikanti et al. 2015; Phillips 2011; Smith 2006; Lush 2006; Eaton and Anthony 2000). If a corresponding author is not fame or 'star', another fame co-author in the authors' list would inevitably introduce some celebrity biases for the corresponding author himself.

Conflict of interest: None.

\section{References}

Bornmann, L., \& Daniel, H.-D. (2009). The state of $h$ index research. Is the $h$ index the ideal way to measure research performance? EMBO Reports, 10(1), 2-6.

Darling, E. S. (2015). Use of double-blind peer review to increase author diversity. Conservation Biology, 29(1), 297-299.

Eaton, K., \& Anthony, H. (2000). Bias in peer review. Journal of the Royal Society of Medicine, 93(6), 338.

Grace, M. (2004). The role of the scientific editor. British Dental Journal, 197(12), 725-734.

http://www.nature.com/nature/authors/get_published. Accessed April, 252015.

Lush, B. (2006). Peer review. Unreliable reviewers. Journal of the Royal Society of Medicine, 99(8), 385.

Mahian, O. (2015). Corresponding authors: Is there fame bias in editorial choice? Nature, 519(7544), 414. 
Manchikanti, L., Kaye, A. D., Boswell, M. V., \& Hirsch, J. A. (2015). Medical journal peer review: Process and bias. Pain Physician, 18(1), E1-E14.

Onitilo, A. A., Engel, J. M., Salzman-Scott, S. A., Stankowski, R. V., \& Doi, S. A. (2013). Reliability of reviewer ratings in the manuscript peer review process: An opportunity for improvement. Accountability in Research, 20(4), 270-284.

Phillips, J. S. (2011). Expert bias in peer review. Current Medical Research and Opinion, 27(12), 22292233.

Smith, R. (2006). Peer review: A flawed process at the heart of science and journals. Journal of the Royal Society of Medicine, 99(4), 178-182.

Spier, R. E. (2002). Peer review and innovation. Science and Engineering Ethics, 8(1), 99-108.

*Email: khaled.moustafa@gmail.com 